\title{
FSH $\beta$ gene mutation in a female with delayed puberty and hypogonadism: response to recombinant human FSH
}

\author{
M.L. Kottler'1, N. Richard', O. Chabre'2, S. Alain ${ }^{1}$, J. Young ${ }^{3}$ \\ ${ }^{1}$ Molecular Genetics, University Hospital F14033 Caen \\ 2Endocrinology, University Hospital, F38000 Grenoble \\ ${ }^{3}$ Endocrinology, University Hospital, F92270 Le Kremlin-Bicętre,
}

\begin{abstract}
We report a woman with primary amenorrhoea and infertility associated with an isolated deficiency of pituitary FSH that does not respond to GnRH administration. Serum inhibin B was undetectable and antimullerian hormone (AMH) was within the normal range. Ultra sound examination revealed a small uterus and small ovaries with few small follicles. We identified an homozygous 1-bp (G) deletion at codon 79 in FSH $\beta$ gene suggesting a complete loss of function. The patient underwent studies of ovarian responsiveness to recombinant human FSH according to the following protocol: 150UI/d for five days following by $75 \mathrm{UI} / \mathrm{d}$ for 10 days. Estradiol plasma level started to increase from day 5 associated to a sharp increase of inhibine B and a decrease of LH. During the same time, we observed an excessive development of multiple follicles resulting in an arrest of the treatment to avoid hyperstimulation. The present study confirm that follicles up to $5 \mathrm{~mm}$ in diameter had developed in the absence of FSH and that FSH is required for the growth of follicles beyond the twolayer granulose stage
\end{abstract}

Key words: FSH $\beta$ mutation, hypogonadism, recombinant hFSH

\section{Introduction}

Human FSH is a heterodimeric pituitary glycoprotein that regulates gonadal function in both sexes. In females, FSH regulates the follicular development and sex-steroid production, whereas in males, FSH stimulates Sertoli cell proliferation and maintenance of sperm quality. These functions are necessary for fertility in both sexes and are supported by studies involving knockout of the FSH $\beta$ gene. Several mutations in FSH $\beta$ gene have been described in humans, and all of those studied by functional analysis demonstrated complete FSH deficiency with absent puberty and infertility.

We report a woman with primary amenorrhoea and infertility associated with an isolated deficiency of pituitary FSH. We identified a new mutation at the homozygous state. Recombinant human FSH was administered in order to study the effect of FSH on follicle development and hormonal production.

Correspondence: ML Kottler, Molecular Genetics, University Hospital F 14033 Caen, France; e-mail: kottler-ml@chu-caen.fr

\section{Patient and Methods}

Patient. The proband presented at 29 years with primary amenorrhea. She is $1.62 \mathrm{~m}$ tall and weighed $62 \mathrm{~kg}$. At clinical examination, she is Tanner stage mammary gland 2 and pubic hair 4 .

There was no family history of delayed puberty and infertility but she was born from consanguineous parents.

The following laboratory test results were obtained: serum FSH was undetectable: $<0.5 \mathrm{mIU} / \mathrm{ml}$ (normal, 2.0 to $17.2 \mathrm{mUI} / \mathrm{ml}$ ) using three different IRMA or EIA assays with monoclonal antibodies and did not response to GnRH administration $(100 \mu \mathrm{g})$; $\mathrm{LH}$ was elevated: $50 \mathrm{mIU} / \mathrm{ml}$ (normal, 1.6 to $9.3 \mathrm{mUI} / \mathrm{ml}$ ) with an explosive response to GnRH. Estradiol was low, between 5 to $15 \mathrm{pg} / \mathrm{ml}$ (normal range in follicular phase 30-90 pg/ml). Prolactine as well as androgens levels were within the normal range. Serum inhibine $\mathrm{B}$ was undetectable and antimullerian hormone (AMH) was within the normal range $(26 \mathrm{pmol} / \mathrm{ml})$.

Ultra sound examination revealed a small uterus and small ovaries with few small follicles.

The patient and her parents gave their consent for genetic screening.

DNA sequencing and analysis. Genomic DNA was extracted from peripheral blood leukocytes using Amersham guidelines. The regions spanning exon 2 and exon 3 which encodes for the FSH $\beta$ subunit protein were amplified using PCR assay, with the following primers: exon 2 forward (AGT TTC TAG TGG GCT TCA TTG TTT G); exon 2 reverse (TGG CTA AAG GAC TCA TGG CTG) 
Table 1. Inactivating mutations described in $\beta$-subunit FSH gene. Prot $\beta$ FSH: $111 \mathrm{AA}$ (without SP); SP, signal peptide; PTC, premature termination codon

\begin{tabular}{|l|c|c|c|c|}
\hline \multicolumn{1}{|c|}{ Nucleotides } & Exon & $\begin{array}{c}\text { Amino acids change } \\
\text { (without SP) }\end{array}$ & $\begin{array}{c}\text { Amino acids change } \\
\text { with SP (18 AA) }\end{array}$ & Reference \\
\hline c.236_237delTG & 3 & Val61X (frameshift, PTC at 86) & Val79X & {$[1,5,6,12]$} \\
\hline c.205T>G & 3 & Cys51Gly & Cys69Gly & {$[1]$} \\
\hline c.298T>C & 3 & Cys82Arg & Cys100Arg & {$[4]$} \\
\hline c.282C $>$ A & 3 & Tyr76X (stop codon) & Tyr94X & {$[3,7]$} \\
\hline c.289delG & 3 & Ala79X (frameshift, PTC at 108) & Ala97X & Present study \\
\hline
\end{tabular}

as previously described [1]; exon 3 forward (AGG AAC TTC CAC AAT ACC ATA ACC TAA C) and exon 3 reverse (CTG CCA GTA GAC CAG GGA TCA GTA GAG).

Briefly, 30 cycles of PCR were performed at $95^{\circ} \mathrm{C}$ for $30 \mathrm{sec}$, $60^{\circ} \mathrm{C}$ for $30 \mathrm{sec}$, and $72^{\circ} \mathrm{C}$ for $40 \mathrm{sec}$. The $\mathrm{MgCl}_{2}$ concentration was $1.5 \mathrm{mM}$. A negative control, containing all reagents except DNA, was included in each PCR. The PCR products were then electrophoresed on agarose gel, purified with Exo-SAP-IT (usb, Ohio, USA) according to manufacture's guidelines, and subjected to dideoxy DNA sequencing using GenomeLab ${ }^{\mathrm{TM}}$ Dye Terminator Cycle Sequencing Kit (DTCS, Beckman Coulter).

MscI digestion. For restriction analysis, MscI (New England BioLabs, Ozyme, france) was used as recommended by the manufacturer and the products were then analyzed on $1.5 \%$ agarose gel electrophoresis with ethidium bromide.

In vivo FSH administration. After giving informed consent and discontinuing the oral contraceptive for one months, the patient underwent studies of ovarian responsiveness to gonadotropins.

The patient was treated by recombinant human FSH (Gonal-F, Serono) according to the following protocol: $150 \mathrm{UI} / \mathrm{d}$ for five days following by $75 \mathrm{UI} / \mathrm{d}$ for 10 days. Hormonal evaluation was made every 5 days and the growth of follicles was monitored by ultra sound examination.

\section{Results}

\section{DNA analysis}

Automated DNA sequencing of exon 2 and exon 3 of FSH $\beta$ gene in the proband, revealed a homozygous 1-bp (G) deletion at codon 79 (Fig. 1A). This deletion results in a frame shift that completely alters the amino acid sequence of FSH $\beta$ subunit from 80 to 108 before leading to a premature stop codon which means that the predicted protein is shorter (Fig. 1B). The deletion of one base pair in codon 79 eliminates a $M s c$ I restriction site in exon 3. Intra familial screening for the mutation was performed using restriction analysis (Fig 2). As expected, the amplified PCR fragment of exon 3 from the proband was not digested by MscI (Fig. 2B, lane III.1-D), whereas wild type fragment of exon 3 was digested into two fragments (Fig. 2B, lane WT-D). Both parents were heterozygous for this variation (Fig. 2B, lanes II.1-D and II.2-D).

\section{Stimulation by r-hFSH}

Estradiol plasma level started to increase from day 5 associated to a sharp increase of inhibin B and a decrease of LH. During the same time, we observed an excessive development of multiple follicles resulting in an arrest of the treatment to avoid hyperstimulation.

\section{Discussion}

The FSH $\beta$ gene (MIM 136530) that codes for the FSH $\beta$-subunit is located on $11 \mathrm{p} 13$ and consists of one noncoding exon plus two translated exons that encode the 129 -aminoacid preprotein. The mature protein consists in 111 amino-acids. To day only 8 subjects (both men and women) with inactivating FSH $\beta$ mutations have been described [1,3-7].

We reported a novel mutation in the $\beta$-subunit FSH gene. If translated, this mutation is predicted to produce a frameshift, altering amino acids 79-108, and then to introduce a stop codon at position 108. According to the crystal structure of hFSH, this variant should interfere with the cystine knot of FSH $\beta$, important for the dimer formation and intracellular stability [2]. In addition, the Ala79Profs108X mutant would be lacking the noose (determinant loop)-amino acids 87-94involved in FSH receptor specificity and the seat belt region contained in amino acids 84-104 that enables the $\beta$-subunit to wrap around the $\alpha$-subunit [2]. Taken together these data suggest a complete loss of function. These finding are similar to that observed for Val61X mutant, excepted for amino acids 61-76, which are conserved with Ala79Profs108X mutant.

Four inactivating mutations, either altering single amino acids or deleting nucleotides leading to premature stop codons and truncated FSH $\beta$-subunit protein (Table 1), have been reported in five female and three male patients [1,3-7]. The phenotypic characteristics caused by these mutations in both sexes are severe, resulting in absent, or incomplete pubertal development and infertility.

This patient was hypoestrogenic with secondary LH excess but not excessive androgen production. 
A

nt 289
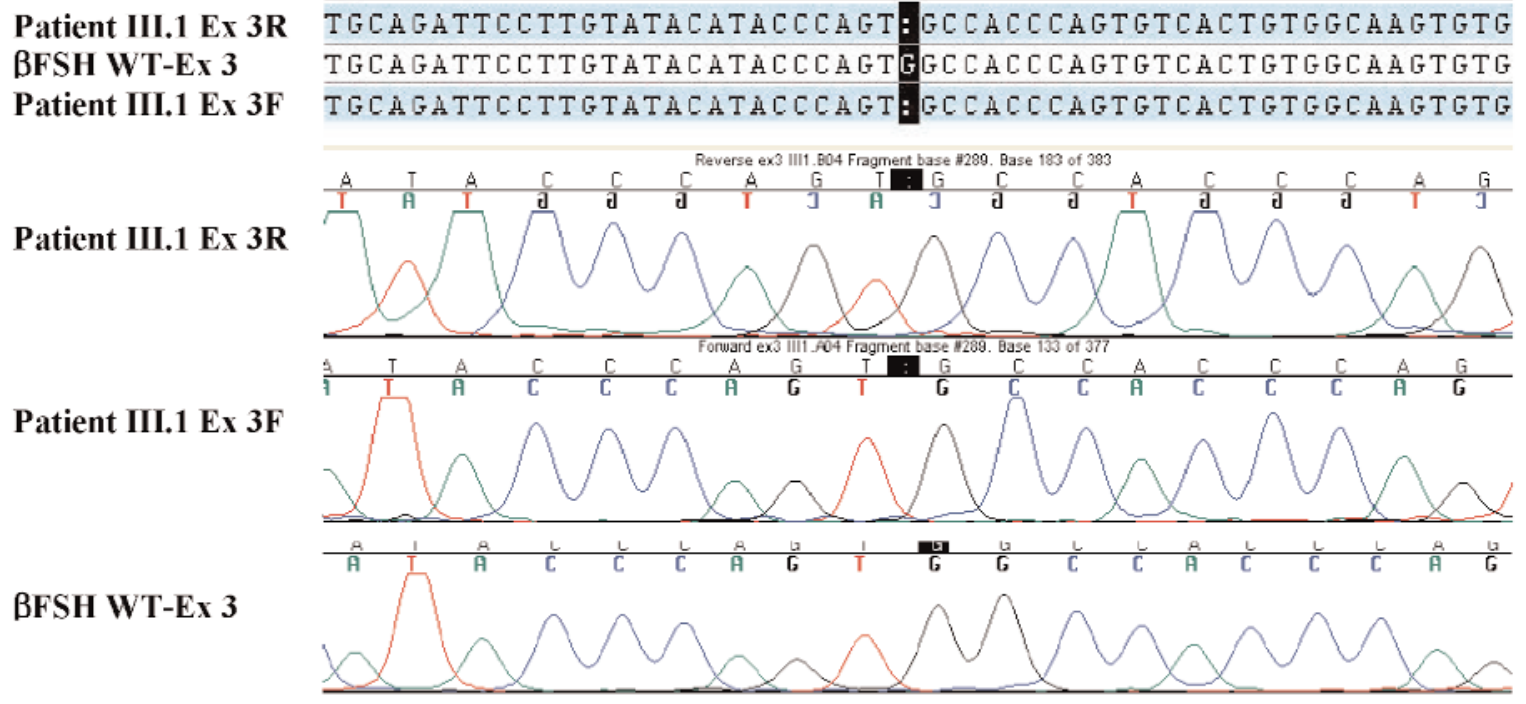

B

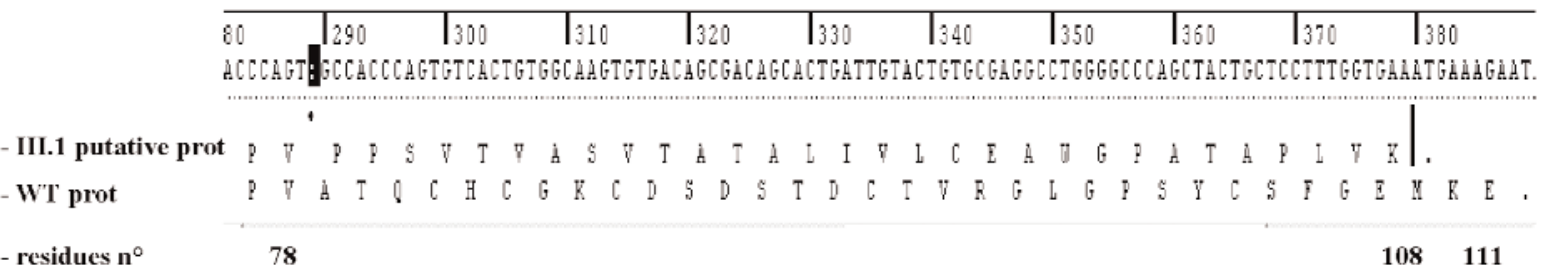

Fig. 1. (A) Characterization of the mutation in the gene for the $\beta$-subunit of Follicle-Stimulating Hormone in a woman with hypogonadism. Sequence analysis of exon 3 of the gene for the $\beta$-subunit, amplified from the patient's DNA III.1 and compared with wild type (WT) DNA, revealed a deletion of one base pair (G) in codon 79 (arrows, c.289delG mutation). (B) Protein alignments between wild type and predicted -subunit peptide of patient III. 1. prot; protein.; WT; wild type

A

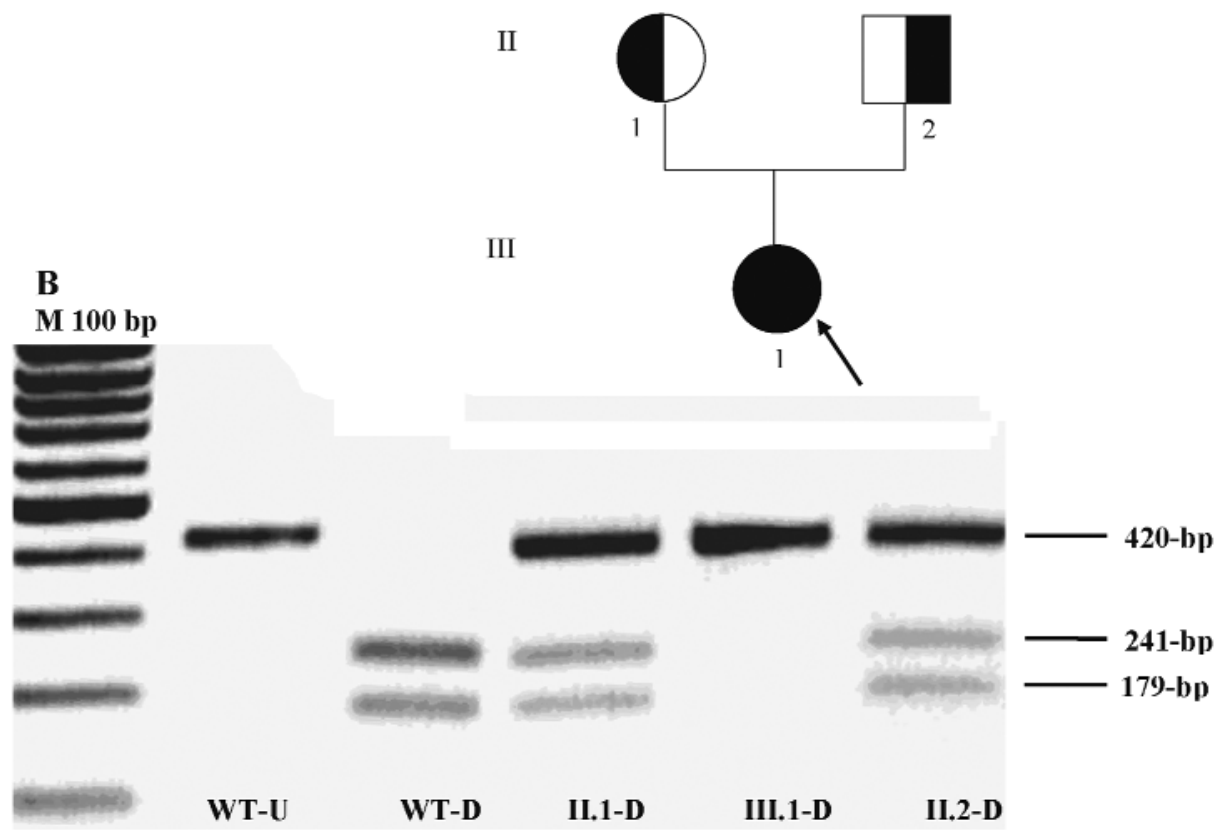

Fig. 2. (A) Pedigrees of the family with FSH deficiency All individuals studied are designated as homozygous (completely black), heterozygous (half-black), or not studied (indicated by question mark). The proband (Subject III.1) is denoted by an arrow. (B) Electrophoresis of a restriction digestion by $\mathrm{MscI}$ of exon 3 PCR product of the FSH $\beta$ gene on $1.5 \%$ agarose gel (with ethidium bromide staining). A restriction site for $\mathrm{Msc}$ I exists in exon 3 of intact fragment resulting to $241-$ and 179-bp short fragment. The variation c. $289 \mathrm{delG}$ eliminates this restriction site resulting to a resistance of mutated fragment to this enzyme. Note the heterozygous pattern of the parental's DNAs (II.1 and II.2). M, mass ladder; WT, wild type; U, undigested; D, MscI digested. 
This finding argues against strict compartmentalization of the action of FSH and LH and suggests the role of paracrine factors (inhibin B being one possibility) stimulated by FSH which in turn stimulate the production of androgen by thecal cells in response to LH [8]. Similar positive regulatory effect of FSH on healthy LH-stimulated Leydig cells was reported in a man with isolated FSH deficiency due to an FSH $\beta$ mutation [9], probably mediated by its primary action on Sertoli cells, in a paracrine mechanism.

We also document the presence of antral follicular development in spite of lack of FSH.

The point at which FSH is necessary for follicular development in the human ovary has been debated for a long time. The present study confirm that follicles up to $5 \mathrm{~mm}$ in diameter had developed in the absence of FSH and that FSH is required for the growth of follicles beyond the two-layer granulose stage [10]. Last, follicles had apparently developed normally since estradiol and inhibin B increased promptly after FSH administration. Our finding is similar to those in other patients with isolated FSH deficiency who ovulated and had successful pregnancy $[5,8,11,12]$.

\section{References}

[1] Layman LC, Lee EJ, Peak DB, et al. Delayed puberty and hypogonadism caused by mutations in the follicle-stimulating hormone beta-subunit gene. N Engl J Med. 1997;337:607-611.

[2] Fox KM, Dias JA, Van Roey P. Three-dimensional structure of human follicle-stimulating hormone. Mol Endocrinol. 2001;15:378-389.

[ 3] Layman LC, Porto AL, Xie J, et al. FSH beta gene mutations in a female with partial breast development and a male sibling with normal puberty and azoospermia. $J$ Clin Endocrinol Metab. 2002;87:3702-3707.

[ 4] Lindstedt G, Nystrom E, Matthews C, et al. Follitropin (FSH) deficiency in an infertile male due to FSHbeta gene mutation. A syndrome of normal puberty and virilization but underdeveloped testicles with azoospermia, low FSH but high lutropin and normal serum testosterone concentrations. Clin Chem Lab Med. 1998;36:663-665.

[ 5] Matthews CH, Borgato S, Beck-Peccoz P, et al. Primary amenorrhoea and infertility due to a mutation in the beta-subunit of follicle-stimulating hormone. Nat Genet. 1993;5:83-86.

[ 6] Phillip M, Arbelle JE, Segev Y, Parvari R. Male hypogonadism due to a mutation in the gene for the beta-subunit of folliclestimulating hormone. N Engl J Med. 1998;338:1729-1732.

[ 7] Berger K, Souza H, Brito VN, et al. Clinical and hormonal features of selective follicle-stimulating hormone (FSH) deficiency due to FSH beta-subunit gene mutations in both sexes. Fertil Steril. 2005;83:466-470.

[ 8] Barnes RB, Rosenfield RL, Namnoum A, Layman LC. Effect of follicle-stimulating hormone on ovarian androgen production in a woman with isolated follicle-stimulating hormone deficiency. $N$ Engl J Med. 2000;343:1197-1198.

[ 9] Lofrano-Porto A, Casulari LA, Nascimento PP, et al. Effects of follicle-stimulating hormone and human chorionic gonadotropin on gonadal steroidogenesis in two siblings with a follicle-stimulating hormone beta subunit mutation. Fertil Steril. 2008;90:1169-1174.

[10] Oktay K, Newton H, Mullan J, Gosden RG. Development of human primordial follicles to antral stages in SCID/hpg mice stimulated with follicle stimulating hormone. Hum Reprod. 1998; 13:1133-1138.

[11] Barnes RB, Namnoum AB, Rosenfield RL, Layman LC. The role of LH and FSH in ovarian androgen secretion and ovarian follicular development: clinical studies in a patient with isolated FSH deficiency and multicystic ovaries. Hum Reprod. 2002;17:88-91.

[12] Matthews C, Chatterjee VK. Isolated deficiency of folliclestimulating hormone re-revisited. $N$ Engl $J$ Med. 1997;337:642. 